\title{
Recurrent mitral regurgitation after annuloplasty for functional ischemic mitral regurgitation
}

Edwin C. McGee, Jr, MD

A. Marc Gillinov, MD

Eugene H. Blackstone, $M D^{\mathrm{a}, \mathrm{b}}$

Jeevanantham Rajeswaran, $\mathrm{MSc}^{\mathrm{b}}$

Gideon Cohen, $\mathrm{MD}^{\mathrm{a}}$

Farzad Najam, MD

Takahiro Shiota, MD ${ }^{\mathrm{c}}$

Joseph F. Sabik, MD

Bruce W. Lytle, MD

Patrick M. McCarthy, MDa

Delos M. Cosgrove, MDa

Electronic appendixes are available online.
From the Departments of Thoracic and Cardiovascular Surgery, ${ }^{a}$ Biostatistics and Epidemiology, ${ }^{\text {b }}$ and Cardiovascular Medicine, ${ }^{\mathrm{c}}$ The Cleveland Clinic Foundation, Cleveland, Ohio.

Read at the Eighty-fourth Annual Meeting of The American Association for Thoracic Surgery, Toronto, Ontario, Canada, April 25-28, 2004.

Received for publication April 23, 2004; revisions received July 22, 2004; accepted for publication July 26, 2004.

Address for reprints: A. Marc Gillinov, MD, The Cleveland Clinic Foundation, 9500 Euclid Ave/Desk F24, Cleveland, OH 44195 (E-mail: gillinom@ccf.org).

J Thorac Cardiovasc Surg 2004;128:916-24 $0022-5223 / \$ 30.00$

Copyright (c) 2004 by The American Association for Thoracic Surgery

doi:10.1016/j.jtcvs.2004.07.037
Objectives: We sought to characterize the temporal return of mitral regurgitation after annuloplasty for functional ischemic mitral regurgitation; to identify its predictors, particularly with respect to annuloplasty type; and to determine whether annuloplasty type influences survival.

Methods: From April 1985 through November 2002, 585 patients underwent annuloplasty alone for repair of functional ischemic mitral regurgitation, generally with concomitant coronary revascularization (95\%). A flexible band (Cosgrove) was used in 68\%, a rigid ring (Carpentier) in $21 \%$, and bovine pericardial annuloplasty (Peri-Guard) in $11 \%$. Six hundred seventy-eight postoperative echocardiograms were available in 422 patients to assess the time course of postoperative mitral regurgitation and its correlates. Most echocardiograms were performed early after the operation (median, 8 days); $17 \%$ were performed at 1 year or beyond.

Results: During the first 6 months after repair, the proportion of patients with 0 or $1+$ mitral regurgitation decreased from $71 \%$ to $41 \%$, whereas the proportion with $3+$ or $4+$ regurgitation increased from $13 \%$ to $28 \%(P<.0001)$; the regurgitation grade was stable thereafter. The temporal pattern of development of $3+$ or $4+$ regurgitation was similar for Cosgrove bands and Carpentier rings (25\%) but substantially worse for Peri-Guard annuloplasties (66\%). Small annuloplasty size did not influence postoperative regurgitation grade $(P=.2)$, although Cosgrove bands were used in most patients receiving 26- and 28-mm annuloplasties. Freedom from reoperation was $97 \%$ at 5 years. Annuloplasty type was not associated with survival.

Conclusions: Although initial mitral valve replacement would eliminate the risk of postoperative mitral regurgitation, this strategy has been associated with reduced survival. Therefore the development of additional techniques is necessary to achieve more secure repair of functional ischemic mitral regurgitation. 


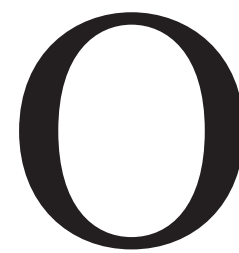

ptimal surgical treatment of functional ischemic mitral regurgitation (IMR) is controversial. Valve repair generally consists of annuloplasty alone, ${ }^{1-4}$ but there is debate concerning the effect of annuloplasty type and size on the durability of repair, and there are few data comparing different annuloplasty strategies..$^{1-3,5-8}$

The objectives of this study were to (1) characterize the temporal return of mitral regurgitation (MR) after annuloplasty alone for functional IMR; (2) to identify risk factors for the return of MR, particularly with respect to annuloplasty type; and (3) to determine whether annuloplasty type influences survival.

\section{Patients and Methods Study Group}

From April 1985 through November 2002, 585 patients underwent annuloplasty alone for repair of functional IMR (see the "Definitions" section) at The Cleveland Clinic Foundation. All had at least $2+$ (moderate) MR on echocardiography, left ventriculography, or both.

Concomitant procedures included coronary artery bypass grafting (585 [95\%] patients) and tricuspid valve repair (62 [11\%] patients). Patients who underwent a concomitant aortic valve procedure or left ventricular restoration were excluded.

Annuloplasty types included the Carpentier-Edwards Classic annuloplasty ring $(\mathrm{n}=122$ [21\%]; Carpentier ring; Edwards Lifesciences, Irvine, Calif), the Cosgrove-Edwards annuloplasty system ( $\mathrm{n}=396$ [68\%]; Cosgrove band; Edwards Lifesciences), and bovine pericardial annuloplasty $(\mathrm{n}=67$ [11\%]; Peri-Guard; Bio-Vascular, Saint Paul, Minn). Early in the series, Carpentier rings were used most commonly, and downsizing was inconsistent. Since 1997, most patients have received Cosgrove bands, with a practice of implanting 26-mm bands in women and 28-mm bands in men (see Electronic Appendixes 1 and 2 available at www.mosby. $\mathrm{com} / \mathrm{jtcvs}$ ). Median annuloplasty size was $28 \mathrm{~mm}$ for Cosgrove bands and $30 \mathrm{~mm}$ for Carpentier rings.

Patient and procedural characteristics are presented in Table 1. Patients receiving Cosgrove bands were more likely to have noncardiac comorbidity and more favorable New York Heart Association functional class but more wall motion abnormalities.

Preoperative echocardiograms were available for analyzing regurgitant jet direction in $477(82 \%)$ patients (Table 2). ${ }^{1}$ Central jet direction was more common when Peri-Guard annuloplasty was used. Regional wall motion abnormalities were documented with echocardiograms or ventriculograms from cardiac catheterization. ${ }^{1}$

\section{Definitions}

MR was considered ischemic when valve leaflets and chordae were normal and MR was caused by consequences of a myocardial infarction ${ }^{1}$; all patients in this study had at least one previous myocardial infarction documented by clinical history or a segmental wall motion abnormality. Among patients with IMR, those with normal papillary muscles, chordae, and leaflets were classified as having functional IMR. Their leaflets failed to coapt, and echocardiograms frequently demonstrated restricted leaflet motion (Carpentier type IIIb leaflet motion). ${ }^{9}$

\section{Progression of MR After Annuloplasty}

Six hundred seventy-eight postrepair echocardiograms were available in $422(75 \%)$ patients to assess the return of MR. These were obtained sporadically, with no set schedule for echocardiographic follow-up. Median time to postrepair echocardiography was 8 days; $75 \%$ (508) of echocardiograms were obtained within the first 2 months after the operation, and 17\% (116) were obtained beyond 1 year. Patients who had a postoperative echocardiogram differed from those who did not; the latter were more likely to be in a higher preoperative New York Heart Association functional class, to have required preoperative intra-aortic balloon pump support, to have had a previous cardiac operation, and to have had more severe preoperative MR (see Electronic Appendixes 3 and 4 available at www.mosby.com/jtcvs).

\section{Reoperation and Survival}

Patients were followed up systematically every 2 years with a mailed questionnaire, telephone interview, or examination. Median follow-up for reoperation and survival was 2.3 years, with 1835 patient-years of follow-up information available for analysis. Among survivors, 25\% were followed up for more than 5 years and $10 \%$ for more than 7 years.

\section{Data Analysis}

Databases used in this study were approved by the institutional review board for use in research.

Selection bias. Because annuloplasty type was not selected randomly, factors associated with increased or decreased probability of a patient receiving a Carpentier ring rather than a Cosgrove band or a Peri-Guard repair rather than a Cosgrove band were identified (see Appendix 1 for variables used in analyses). ${ }^{10}$ From these 2 analyses, we calculated the probabilities of receiving (1) a Cosgrove band, (2) a Carpentier ring, and (3) a Peri-Guard repair (see Electronic Appendix 5 available at www.mosby.com/ jtcvs) for each patient. These probabilities were used as balancing scores to reduce selection bias in all analyses of outcome. ${ }^{11,12}$

Progression of MR after annuloplasty. To estimate the prevalence of each MR grade across follow-up time, longitudinal ordinal regression for repeated measurements was used (see Electronic Appendix 5). Results are accompanied by crude estimates of prevalence of each grade within sequential time frames.

Factors influencing the return of MR. Factors influencing the temporal pattern of MR after annuloplasty were identified separately for the rapidly changing early period (first 6 months after repair) and the stable phase thereafter. In each case, type of annuloplasty and its balancing score were included in the analyses, regardless of statistical significance. Other factors were sought by using the candidate variables in Appendix 1. 
TABLE 1. Patient characteristics overall and by annuloplasty type

\begin{tabular}{|c|c|c|c|c|c|c|}
\hline Characteristics & $n^{*}$ & $\begin{array}{c}\text { Entire group } \\
(\mathbf{n}=585) \\
\text { No. }(\%)\end{array}$ & $\begin{array}{c}\text { Cosgrove } \\
\text { (n = 396 } \\
[68 \%]) \\
\text { No. }(\%)\end{array}$ & $\begin{array}{c}\text { Carpentier } \\
\text { (n = 122 } \\
[21 \%]) \\
\text { No. }(\%)\end{array}$ & $\begin{array}{c}\text { Peri-Guard } \\
\text { (n = 67 } \\
[11 \%]) \\
\text { No. }(\%)\end{array}$ & $P$ value \\
\hline \multicolumn{7}{|l|}{ Demographic } \\
\hline Age (y) & 585 & & & & & .2 \\
\hline$<50$ & & $30(5)$ & $17(4)$ & $9(7)$ & $4(6)$ & \\
\hline$\geq 50-60$ & & $100(17)$ & $72(18)$ & $21(17)$ & $7(10)$ & \\
\hline$\geq 60-70$ & & $220(38)$ & $152(38)$ & $36(30)$ & $32(48)$ & \\
\hline$\geq 70$ & & $235(40)$ & $155(39)$ & $56(64)$ & $24(36)$ & \\
\hline Male sex & 585 & $350(60)$ & $244(62)$ & $64(52)$ & $42(63)$ & .2 \\
\hline \multicolumn{7}{|l|}{ Cardiac comorbidity } \\
\hline NYHA functional class & 581 & & & & & .0008 \\
\hline I & & $3(0.5)$ & $2(0.5)$ & $1(0.84)$ & $0(0)$ & \\
\hline II & & $216(37)$ & $159(40)$ & $35(29)$ & $22(33)$ & \\
\hline III & & $236(41)$ & $170(43)$ & $44(37)$ & $22(33)$ & \\
\hline IV & & $126(22)$ & $64(16)$ & $39(33)$ & $23(34)$ & \\
\hline Emergency operation & 584 & $14(2)$ & $9(2)$ & $1(0.8)$ & $4(6)$ & .08 \\
\hline Preoperative IABP & 585 & $88(15)$ & $50(13)$ & $24(20)$ & $14(21)$ & .06 \\
\hline Coronary system disease $(>50 \%)$ & 585 & & & & & .3 \\
\hline 0 & & $8(2)$ & $8(2)$ & $0(0)$ & $0(0)$ & \\
\hline 1 & & $45(8)$ & $30(8)$ & $9(7)$ & $6(9)$ & \\
\hline 2 & & $116(20)$ & $75(19)$ & $23(19)$ & $18(27)$ & \\
\hline 3 & & $416(71)$ & $283(71)$ & $90(74)$ & $43(64)$ & \\
\hline $\begin{array}{c}\text { MI within } 14 \text { days of } \\
\text { operation (acute) }\end{array}$ & 585 & $96(16)$ & $70(18)$ & $14(12)$ & $12(18)$ & .2 \\
\hline Left ventricular dysfunction & 584 & & & & & .4 \\
\hline None & & $48(8)$ & $36(9)$ & $9(7)$ & $3(4)$ & \\
\hline Mild & & $94(16)$ & $69(17)$ & $18(15)$ & $7(10)$ & \\
\hline Moderate & & $210(36)$ & $136(35)$ & $43(35)$ & $31(46)$ & \\
\hline Severe & & $232(40)$ & $154(39)$ & $52(43)$ & $26(39)$ & \\
\hline \multicolumn{7}{|l|}{ Wall motion abnormality } \\
\hline Anterior & 544 & $305(56)$ & $223(59)$ & $55(51)$ & $27(47)$ & .1 \\
\hline Septal & 544 & $330(61)$ & $253(67)$ & $53(49)$ & $24(41)$ & $<.0001$ \\
\hline Posterior & 542 & $401(74)$ & $290(77)$ & $75(69)$ & $36(62)$ & .02 \\
\hline Lateral & 542 & $310(57)$ & $237(63)$ & $50(46)$ & $23(40)$ & .0001 \\
\hline Inferior & 544 & $468(86)$ & 332 (88) & $94(87)$ & $42(72)$ & .006 \\
\hline Atrial fibrillation & 585 & $55(9)$ & 37 (9) & $6(5)$ & $12(18)$ & .01 \\
\hline Previous CABG & 585 & $182(31)$ & $119(30)$ & $40(33)$ & $23(34)$ & .7 \\
\hline \multicolumn{7}{|l|}{ Noncardiac comorbidity } \\
\hline Hypertension & 563 & $407(72)$ & $287(76)$ & $78(67)$ & $42(65)$ & .06 \\
\hline COPD & 557 & $154(27)$ & $124(32)$ & $19(20)$ & $11(17)$ & .009 \\
\hline Diabetes & 566 & $197(35)$ & $150(39)$ & $26(22)$ & $21(34)$ & .005 \\
\hline Renal disease & 585 & $59(10)$ & $42(11)$ & $13(11)$ & $4(6)$ & .5 \\
\hline \multicolumn{7}{|l|}{ Procedure } \\
\hline Tricuspid valve repair & 585 & $62(11)$ & 47 (12) & $9(7)$ & $6(9)$ & .3 \\
\hline CABG & 585 & 554 (95) & $370(93)$ & 118 (97) & $66(98)$ & .1 \\
\hline
\end{tabular}

NYHA, New York Heart Association; IABP, intra-aortic balloon pump; $M I$, myocardial infarction; CABG, coronary artery bypass grafting; COPD, chronic obstructive pulmonary disease.

*Data available.

Mitral valve replacement. Nonparametric and parametric ${ }^{13}$ methods were used to estimate freedom from mitral valve replacement after annuloplasty. The number of events was too small to compare annuloplasty type.
Survival. Nonparametric and parametric multiphase hazardbased methods ${ }^{13}$ were used to estimate survival. Risk factors associated with the 2 hazard phases resolved were identified by using multivariable analyses with bagging, ${ }^{14}$ according to the 
TABLE 2. Preoperative mitral valve pathophysiology by echocardiography and Doppler interrogation

\begin{tabular}{|c|c|c|c|c|c|}
\hline Pathology & $\begin{array}{c}\text { Entire group, } \\
\text { no. }(\%)\end{array}$ & $\begin{array}{c}\text { Cosgrove, } \\
\text { no. }(\%)\end{array}$ & $\begin{array}{c}\text { Carpentier, } \\
\text { no. }(\%)\end{array}$ & $\begin{array}{c}\text { Peri-Guard, } \\
\text { no. }(\%)\end{array}$ & $P$ value \\
\hline MR jet direction (n) & 477 & 340 & 87 & 50 & \\
\hline Central & $313(66)$ & $218(64)$ & $54(62)$ & $41(82)$ & .03 \\
\hline Anterior & $12(2.5)$ & $8(2.4)$ & $3(3.4)$ & $1(2.0)$ & .8 \\
\hline Posterior & $110(23)$ & $89(26)$ & $18(21)$ & $3(6)$ & .006 \\
\hline Complex & $42(9)$ & $25(7)$ & $12(14)$ & $5(10)$ & .2 \\
\hline MR grade $(n)$ & 585 & 396 & 122 & 67 & .03 \\
\hline $2+$ & $90(15)$ & $74(19)$ & $11(9)$ & $5(7)$ & \\
\hline $3+$ & $288(49)$ & $185(47)$ & $65(53)$ & $38(57)$ & \\
\hline $4+$ & $207(35)$ & $137(35)$ & $46(38)$ & $24(36)$ & \\
\hline
\end{tabular}

MR, Mitral regurgitation.

*Data available.

methodology described in Electronic Appendix 5. ${ }^{15}$ Variables indicating annuloplasty type and their balancing scores were included in each hazard phase.

Presentation. Mortality and survival estimates are accompanied by asymmetric $68 \%$ confidence intervals, which are comparable to $\pm 1 \mathrm{SE}$.

\section{Results}

\section{Progression of MR After Annuloplasty}

Although high-grade $(3+$ or $4+)$ MR was uncommon immediately postoperatively, the degree of MR changed rapidly during the first 6 months and then became relatively stable (Figure 1, A). Overall, $28 \%$ of patients had $3+$ or $4+$ MR 6 months after the operation (Figure 1,B). Six months after Peri-Guard annuloplasty, $66 \%$ of patients had $3+$ or $4+$ MR (Figure 2). In contrast, early and late grades of MR were similar in patients receiving Cosgrove bands and Carpentier rings; with each, approximately $25 \%$ of patients had $3+$ or $4+\mathrm{MR}$ in the first 6 months after the operation (Figure 2).

\section{Risk Factors for the Return of MR}

Peri-Guard annuloplasty, higher grade of preoperative MR, and jet direction other than posterior (essentially central or complex) were associated with early return of MR (Table 3). Peri-Guard annuloplasty and more severe preoperative left ventricular dysfunction were risk factors for late return. Larger annuloplasty band or ring size was not identified as a risk factor for recurrent MR.

\section{Mitral Valve Replacement}

Eleven patients had mitral valve replacement during followup, with a 5-year freedom from reoperation of $97 \%$.

\section{Survival}

There were 37 hospital deaths (6.3\%); survival was $82 \%$ at 1 year and $60 \%$ at 5 years. After accounting for other factors, neither annuloplasty type nor size was associated with time-related survival (see Electronic Appendix 6 available at www.mosby.com/jtcvs).

\section{Discussion}

Several recent studies address the effect of surgical strategy (repair versus replacement and annuloplasty type in repair patients) on outcome in patients with IMR. ${ }^{1-3,5-8}$ Although it is accepted that valve repair is superior to replacement in most patients, ${ }^{1-3}$ considerable controversy remains concerning the choice of annuloplasty technique in those who undergo repair. ${ }^{3,4,9}$ Key findings of this study are that (1) during the first 6 months after annuloplasty for functional IMR, important MR returns in many patients; (2) it does so considerably more often after pericardial annuloplasty than after Cosgrove band and Carpentier ring annuloplasty; (3) subsequent mitral valve replacement is uncommon; and (4) annuloplasty type does not appear to affect survival.

\section{Progression of MR After Annuloplasty}

Functional IMR results from alterations in ventricular and annular geometry that decrease leaflet coaptation. Annuloplasty increases leaflet coaptation by decreasing the septallateral (anterior-posterior) dimension of the mitral annulus, ${ }^{2}$ which does not address all mechanisms of functional IMR. $^{16}$

Annuloplasty alone does not ensure successful and durable elimination of MR..$^{5-9,16-18}$ Previous reports document that $17 \%$ to $29 \%$ of patients experience early or late return of $2+$ or greater MR..$^{5-9,16-18}$ However, these studies are small, and follow-up is limited, precluding detailed characterization of the temporal pattern of MR return. Furthermore, comparison between studies might be problematic because of different grading systems (eg, Is moderate MR defined as $2+$ or $3+$ ?).

Analysis of 678 postoperative echocardiograms obtained from a few days to 8 years postoperatively enabled us to examine the course of MR after annuloplasty. Most echo- 

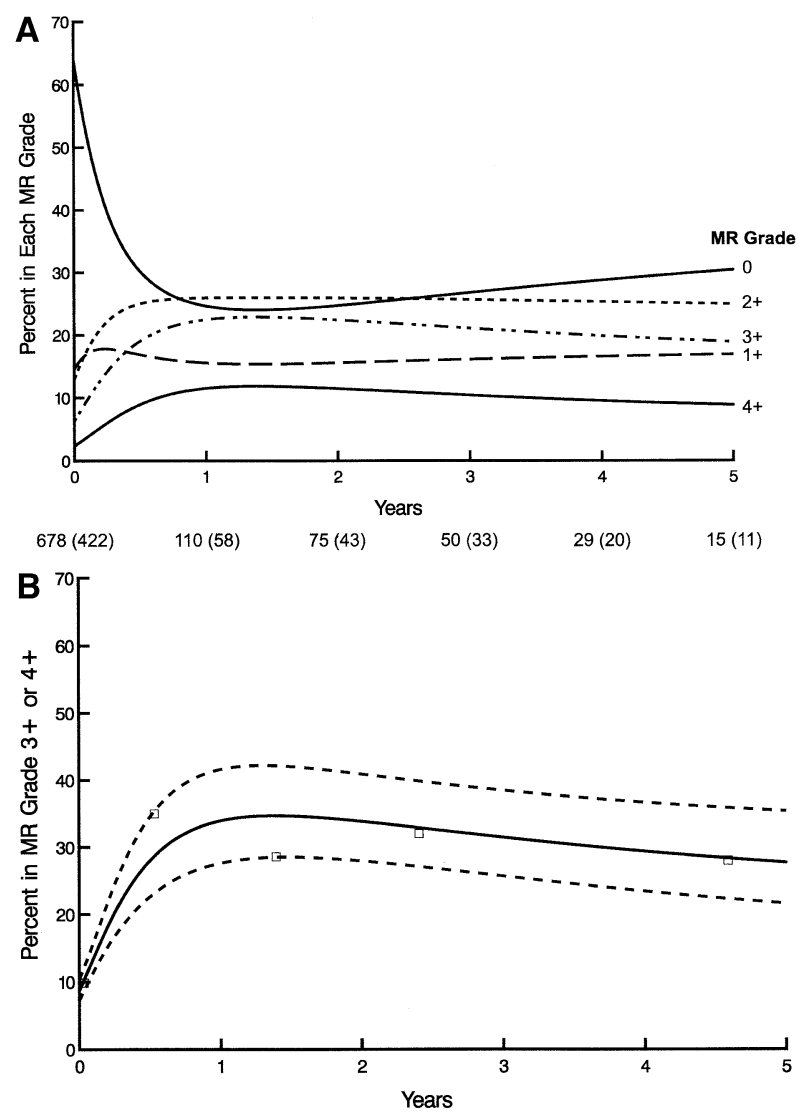

Figure 1. Progression of MR after surgical annuloplasty overall. A, All grades of MR. Curves for each regurgitation grade represent average temporal prevalence, and they sum to $100 \%$ at each point in time. Numbers below the horizontal axis represent echocardiograms available at various time points, with the number of patients in parentheses. B, Prevalence of regurgitation grades $3+$ or $4+$. Symbols represent crude estimates of grouped raw data. Dashed lines are $68 \%$ confidence limits of average prevalence.

cardiograms were obtained within 1 year of the operation, when estimates of MR degree are most reliable. MR is dynamic in the first 6 months after the operation and stabilizes thereafter.

\section{Risk Factors for Return of MR}

Some studies have demonstrated that various forms of suture annuloplasty are less durable than a prosthetic band or ring, ${ }^{5,7,8}$ but von Oppell and colleagues ${ }^{17}$ report no difference. Posterior suture annuloplasty with pericardial buttressing used in this study failed to provide durable repair. The pattern of MR return was similar to that for Cosgrove bands and Carpentier rings. Few other reports compare different prosthetic annuloplasty techniques. In a smaller study with follow-up extending to only 6 weeks postoperatively, Aklog and associates ${ }^{9}$ found that complete resolution of IMR was more likely with Carpentier rings than with

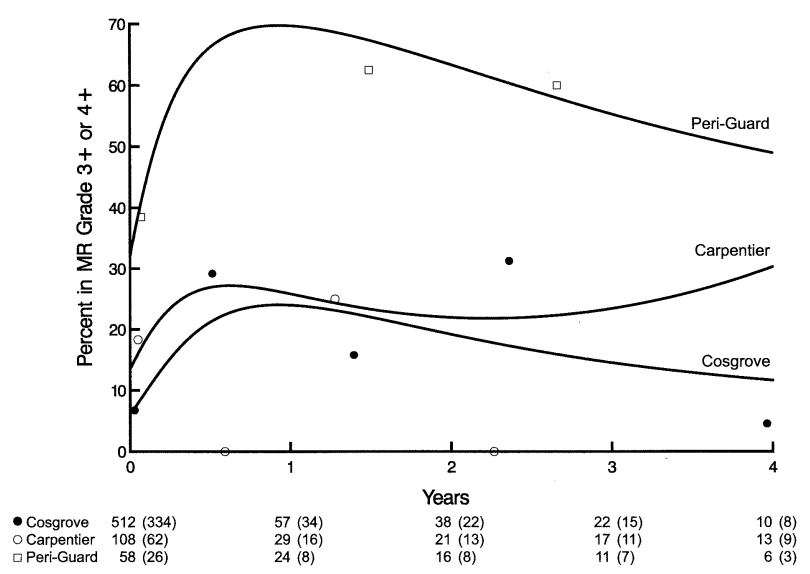

Figure 2. The effect of annuloplasty type on return of $3+$ or $4+$ mitral regurgitation. The number of echocardiograms available at various time points is indicated, with the number of patients in parentheses. Symbols represent crude estimates of grouped raw data. Carpentier, Carpentier-Edwards Classic annuloplasty ring; Cosgrove, Cosgrove-Edwards annuloplasty system; Peri-Guard, bovine pericardial annuloplasty.

Cosgrove bands, although, as in our study, the prevalence of residual $2+$ MR or greater was similar.

Recent experimental and human data confirm that the anterior mitral annular dimension and intertrigonal distance dilate in IMR. ${ }^{19-21}$ Some have suggested that this supports use of a complete remodeling annuloplasty in patients with IMR. ${ }^{20,21}$ However, it is reduction of the septal-lateral dimension that is most important. ${ }^{2}$ Prosthetic ring or band annuloplasty more effectively reduces this diameter than does suture annuloplasty, ${ }^{7}$ perhaps explaining the difference in efficacy between these 2 techniques. However, data examining the effect of different prosthetic annuloplasty techniques on septal-lateral diameter are lacking.

In addition to debate over annuloplasty type, there is considerable discussion about annuloplasty size in patients with functional IMR. Most surgeons advocate an undersized annuloplasty to achieve the greatest reduction in septallateral dimension. ${ }^{4,22,23}$ In patients with ischemic and nonischemic cardiomyopathies, Bolling and coworkers ${ }^{22,23}$ have achieved excellent early and midterm results with an undersized flexible annuloplasty ring. However, there are few available data to answer the following question: How small should the annuloplasty be? Like Tahta, ${ }^{6}$ Aklog, ${ }^{9}$ and their colleagues, we found poor correlation between annuloplasty size and the return of MR. However, most of our patients received small annuloplasties (label size of 26, 28, or $30 \mathrm{~mm}$ ); it is possible that had more patients received larger-sized annuloplasties, a difference in durability might have been detected. In addition, no patient received a 24-mm annuloplasty, and those in whom a Carpentier ring was inserted received the largest sizes. Therefore, the effect 
TABLE 3. Risk factors related to higher postoperative MR grade

\begin{tabular}{|c|c|c|}
\hline Risk factor & Coefficient \pm SE & $P$ value \\
\hline \multicolumn{3}{|l|}{ Early MR grade change (0-6 mo) } \\
\hline Higher preoperative MR grade ${ }^{*}$ & $0.12 \pm 0.025$ & $<.0001$ \\
\hline Smaller body sizet & $-2.8 \pm 0.81$ & .0007 \\
\hline No ITA graft used & $0.68 \pm 0.22$ & .002 \\
\hline Jet direction other than posterior & $-0.54 \pm 0.28$ & .05 \\
\hline No preoperative tricuspid regurgitation & $-0.57 \pm 0.26$ & .03 \\
\hline Earlier date of operation & $-0.101 \pm 0.039$ & .009 \\
\hline \multicolumn{3}{|l|}{ Interaction } \\
\hline Peri-Guard and earlier date of operation $\ddagger$ & $-0.59 \pm 0.17$ & .0006 \\
\hline \multicolumn{3}{|l|}{ Annuloplasty type } \\
\hline Cosgrove vs Carpentier & $-0.31 \pm 0.33$ & .4 \\
\hline Peri-Guard vs Carpentier & $5.2 \pm 1.4$ & .0002 \\
\hline \multicolumn{3}{|l|}{ Balancing scores } \\
\hline P_Cosgrove§ & $0.53 \pm 0.71$ & .4 \\
\hline P_Peri-Guard\| & $-0.29 \pm 0.99$ & .8 \\
\hline \multicolumn{3}{|l|}{ Late MR grade change (>6 mo) } \\
\hline Female sex & $0.99 \pm 0.502$ & .05 \\
\hline Higher LV dysfunction grade\# & $1.2 \pm 0.57$ & .03 \\
\hline Higher preoperative MR grade* & $0.095 \pm 0.052$ & .06 \\
\hline \multicolumn{3}{|l|}{ Annuloplasty type } \\
\hline Cosgrove vs Carpentier & $-0.64 \pm 0.57$ & .3 \\
\hline Peri-Guard vs Carpentier & $1.9 \pm 0.72$ & .008 \\
\hline \multicolumn{3}{|l|}{ Balancing scores } \\
\hline P_Cosgrove§ & $0.085 \pm 1.8$ & $>.9$ \\
\hline P_Peri-Guard\| & $-1.9 \pm 1.5$ & .2 \\
\hline
\end{tabular}

$M R$, Mitral regurgitation; ITA, internal thoracic artery; $L V$, left ventricular.

*(Preoperative mitral regurgitation $)^{2}$ squared transformation.

†Ln(body surface area) logarithmic transformation.

$\ddagger$ Peri-Guard annuloplasty with date of operation (interaction term).

§Probability of patient receiving Cosgrove band.

|Probability of patient receiving Peri-Guard annuloplasty.

\#Left ventricular dysfunction (grades 3 or 4 vs 1 or 2 ; yes/no).

of small remodeling rigid annuloplasty (Carpentier ring) could not be examined.

Several clinical factors were associated with the return of MR. These included a higher grade of preoperative MR and more severe left ventricular dysfunction. Von Oppell and colleagues ${ }^{17}$ found that these factors increased the risk of MR recurrence after suture or ring annuloplasty, and Aklog and associates ${ }^{9}$ identified a higher grade of preoperative MR as a risk factor for greater postoperative MR. Others have failed to confirm these relationships. ${ }^{6}$ Jet direction also influenced repair durability; a central jet might indicate restriction of both the anterior and posterior leaflets, causing more severe leaflet tenting and making restoration of coaptation less probable. ${ }^{24}$

\section{Mitral Valve Replacement}

Although return of MR was common, mitral valve replacement was not. There are several possible explanations for this observation. First, because nearly half of the patients died within 5 years of the operation, the competing risk of death might have limited the number of patients available for reoperation. Second, IMR after annuloplasty might be considered inconsequential compared with the underlying myocardial disease. Third, surgeons might be hesitant to perform a second or third cardiac operation in these elderly, high-risk patients.

\section{Survival}

As in other studies of patients with IMR, survival was limited. ${ }^{1-3}$ Although our previous study demonstrated that pericardial annuloplasty reduced survival in patients with IMR undergoing mitral valve repair, the analysis included patients with all forms of IMR, including papillary muscle pathology. In contrast, this study focuses on that subset of patients with functional IMR, and in this population we found little association between annuloplasty type and survival. These results do not preclude a survival effect of other annuloplasty techniques not used in this study. In fact, comparing suture annuloplasty with a remodeling ring, Grossi and coworkers ${ }^{5}$ demonstrated reduced survival with 
suture annuloplasty. However, other studies have failed to identify annuloplasty type as a risk factor. ${ }^{9,17}$

\section{Limitations}

Most of this study's findings are based on analysis of postoperative echocardiograms. Systematic scheduling of echocardiographic follow-up is not possible outside a clinical trial. ${ }^{1,6,9}$ Although most patients had a predischarge echocardiogram, late echocardiograms were obtained sporadically at the cardiologists' discretion. Comparing patients who received postoperative echocardiograms with those who did not revealed some differences (see Electronic Appendixes 3 and 4). Patients without postoperative echocardiograms had a higher degree of preoperative MR, a factor related to more severe postoperative MR. This suggests that high-grade postoperative MR might be underestimated. Most echocardiograms were obtained in the first year after the operation, the time of greatest change in MR grade. However, $17 \%$ of echocardiograms were obtained beyond that point, providing sufficient data to characterize the temporal pattern of MR.

Because this was not a randomized study, there were differences among patients receiving different annuloplasty types. Multivariable analyses and balancing scores were used to account for these differences.

It is possible that detailed analysis of preoperative echocardiographic dimensions will reveal quantifiable risk factors for annuloplasty failure. In fact, Calafiore and associates ${ }^{24}$ has suggested that excessive leaflet tenting jeopardizes repair.

We cannot address in a formal fashion the relationship between progression of MR and survival. Others have suggested that MR recurrence jeopardizes survival, ${ }^{9,17}$ but to our knowledge, statistical methodology to test this hypothesis properly does not exist. Both recurrent MR and death are outcomes of surgical intervention. Examination of their interdependence and their relationship to surgical technique requires the development of novel statistical methodology.

\section{Clinical Inferences}

A prosthetic annuloplasty band or ring should be used in patients with functional IMR. During the first 6 months thereafter, patients should be followed closely by using echocardiography. Although initial mitral valve replacement would eliminate the risk of postoperative MR, this strategy is associated with reduced survival in most patients with IMR. ${ }^{1}$ Therefore, development of additional techniques is necessary to achieve more secure repair of functional IMR.

\section{References}

1. Gillinov AM, Wierup PN, Blackstone EH, et al. Is repair preferable to replacement for ischemic mitral regurgitation? J Thorac Cardiovasc Surg. 2001;122:1125-41.
2. Miller DC. Ischemic mitral regurgitation redux-to repair or to replace? J Thorac Cardiovasc Surg. 2001;122:1059-62.

3. Grossi EA, Goldberg JD, LaPietra A, et al. Ischemic mitral valve reconstruction and replacement: comparison of long-term survival and complications. J Thorac Cardiovasc Surg. 2001;122:1107-24.

4. Adams DH, Filsoufi F, Aklog L. Surgical treatment of the ischemic mitral valve. J Heart Valve Dis. 2002;11(suppl 1):S21-5.

5. Grossi EA, Bizekis CS, LaPietra A, et al. Late results of isolated mitral annuloplasty for "functional" ischemic mitral insufficiency. J Card Surg. 2001;16:328-32.

6. Tahta SA, Oury JH, Maxwell JM, et al. Outcome after mitral valve repair for functional ischemic mitral regurgitation. J Heart Valve Dis. 2002;11:11-9.

7. Czer LS, Maurer G, Trento A, et al. Comparative efficacy of ring and suture annuloplasty for ischemic mitral regurgitation. Circulation. 1992;86(suppl II):II46-52.

8. Czer LS, Maurer G, Bolger AF, et al. Revascularization alone or combined with suture annuloplasty for ischemic mitral regurgitation. Evaluation by color Doppler echocardiography. Tex Heart Inst J. 1996;23:270-8.

9. Aklog L, Soltesz EG, Filsoufi F, et al. The impact of residual mitral regurgitation on survival after CABG and annuloplasty for ischemic mitral regurgitation. J Thorac Cardiovasc Surg. 2004. In press.

10. Rosenbaum PR, Rubin DB. The central role of the propensity score in observational studies for causal effects. Biometrika. 1983;70:41-55.

11. Blackstone EH. Comparing apples and oranges. J Thorac Cardiovasc Surg. 2002;123:8-15.

12. Rubin DB. Estimating causal effects from large data sets using propensity scores. Ann Intern Med. 1997;127:757-63.

13. Blackstone EH, Naftel DC, Turner ME Jr. The decomposition of time-varying hazard into phases, each incorporating a separate stream of concomitant information. J Am Stat Assoc. 1986;81:615-24.

14. Breiman L. Bagging predictors. Machine Learning. 1996;24:123-40.

15. Blackstone EH, Rice TW. Clinical-pathologic conference: use and choice of statistical methods for the clinical study, "superficial adenocarcinoma of the esophagus." J Thorac Cardiovasc Surg. 2001;122: 1063-76.

16. Lachmann J, Shirani J, Plestis KA, et al. Mitral ring annuloplasty: an incomplete correction of functional mitral regurgitation associated with left ventricular remodeling. Curr Cardiol Rep. 2001;3:241-6.

17. von Oppell UO, Stemmet F, Brink J, et al. Ischemic mitral valve repair surgery. J Heart Valve Dis. 2000;9:64-74.

18. Akar AR, Doukas G, Szafranek A, et al. Mitral valve repair and revascularization for ischemic mitral regurgitation: predictors of operative mortality and survival. J Heart Valve Dis. 2002;11:793-80 1

19. Gorman JH 3rd, Gorman RC, Jackson BM, et al. Annuloplasty ring selection for chronic ischemic mitral regurgitation: lessons from the ovine model. Ann Thorac Surg. 2003;76:1556-63.

20. Tibayan FA, Rodriguez F, Langer F, et al. Annular remodeling in chronic ischemic mitral regurgitation: ring selection implications. Ann Thorac Surg. 2003;76:1549-55.

21. Hueb AC, Jatene FB, Moreira LF, et al. Ventricular remodeling and mitral valve modifications in dilated cardiomyopathy: new insights from anatomic study. J Thorac Cardiovasc Surg. 2002;124:1216-24.

22. Bolling SF, Pagani FD, Deeb GM, et al. Intermediate-term outcome of mitral reconstruction in cardiomyopathy. $J$ Thorac Cardiovasc Surg. 1998; 115:381-8.

23. Smolens IA, Bolling SF. Surgical approaches to dilated cardiomyopathy. Curr Cardiol Rep. 2000;2:99-105.

24. Calafiore AM, Gallina S, Di Mauro M, et al. Mitral valve procedure in dilated cardiomyopathy: repair or replacement? Ann Thorac Surg. 2001;71:1146-53.

\section{Discussion}

Dr D. Craig Miller (Stanford, Calif). Thank you, Dr McGee, for a very fine presentation. You should be proud. Number one, I would like to compliment The Cleveland Clinic Foundation for your honesty. This is an important contribution. 
Unlike mitral valve prolapse, in which the standard of care is to leave zero or negligible residual MR after repair, surgeons have played ostrich for far too long in overlooking the repair failures that we leave behind in patients with IMR. Why have we overlooked these shortcomings? For one, in many cases we most likely were just glad to have a survivor.

The debate about whether you should intervene in those cases with moderate IMR when you are performing coronary revascularization remains open, but most of the world now thinks you should do something to the valve if the degree of MR is more than $2+$ on a preoperative transthoracic echocardiogram.

I have one minor quibble-despite being a believer in Gene Blackstone's statistical magic-which concerns the echocardiographic data. The median time for all echocardiographic studies was only 8 days postoperatively; you had an echocardiogram within 2 months in $75 \%$ of patients but beyond 1 year in only $17 \%$. Yet your curves showing the recurrent rates of MR were drawn way out to 4 and 5 years, and I did not see any confidence levels or variability of the estimates, which I would expect from Dr Blackstone. Are you not extrapolating beyond what the data set reliably allows?

Dr McGee. Thank you very much for your comments, Dr Miller. We are all very much indebted to you for furthering our understanding of the complex functional anatomy of the mitral valve.

To answer your question, it is true that most of our echocardiograms were early, and $17 \%$, as you mentioned, were after 1 year, but we did have points out to that far, and we believe our data. In addition, the echocardiograms that were obtained sporadically were done so in symptomatic patients, and it also seemed to be in patients who had more complex jets. Therefore it is likely that we were somewhat pessimistic in the return of MR, and if there is any error, it is going to be an overestimate of recurrent MR.

Dr Miller. Were these postoperative studies all Cleveland Clinic echocardiograms?

Dr McGee. Yes, they were all Cleveland Clinic echocardiograms, and they were all transthoracic studies.

Dr Miller. That explains why you do not have too many late studies, even though many were probably done elsewhere. I could turn your argument against you and speculate that this is actually an overly rosy estimate of the recurrent rate of IMR because you do not have complete echocardiographic follow-up information. Perhaps those with more severe recurrent MR and poorer left ventricular (LV) function had succumbed and therefore did not return to get a Cleveland Clinic Foundation postoperative echocardiogram. But that is an imponderable result, so let's drop it for now.

On your echocardiographic studies, were there any substantial mitral gradients? This is pertinent because in Dr Rankin's and Dr Glower's article, they were using 24- to 26-mm rings. What was the average mitral mean gradient? Are we creating any important degree of functional mitral stenosis by using these teeny rings?

Dr McGee. To my knowledge, there were not any gradients created by overdownsizing.

Dr Miller. Finally, in 2002-2003, use of the Cosgrove band dipped, whereas use of the Carpentier-Edwards Classic ring increased. What is the current practice today since the completion of this study?
Dr McGee. That would depend on which surgeon you spoke with.

Dr Miller. A very prudent answer; that is what I thought you would say.

Regarding the reoperation rate, it is low, with $97 \%$ free at 5 years, and you give us 3 reasons in the article why that might be so. Interestingly, that was the identical number Dr Glower just presented. But is it really fair to compare reoperation rates after repair for prolapse with reoperation for IMR? That is an apples to oranges comparison and just does not compute. I would wager that many patients with recurrent MR were just too sick or too old or both to even consider reoperating on them, which is distinctly different than younger patients after prolapse repair; this might be the main reason why even though $25 \%$ had severe MR 6 months later, more did not undergo reoperation. Would you agree?

Dr McGee. Yes, sir.

Dr Miller. That represents good judgment.

Dr Bruce W. Lytle (Cleveland, Ohio). I would like to interject something here. The interesting thing about it is, though, that the unadjusted survival rate of these patients is also identical to the unadjusted survival rate of Dr Glower's and Dr Rankin's patients, which is $55 \%$ at 5 to 6 years. Therefore whatever is going on there, these are very similar groups of patients in terms of survival.

Dr Miller. That is a good point, Bruce.

Finally, if we can break through our denial, which is always tough for a surgeon, and accept that simple ring annuloplasty is not enough for patients with IMR, is there anything we can add to a ring at the ventricular level to improve things, such as a Coapsys device or other method of LV reshaping? Or should we swallow our pride and do a straightforward, quick, and reliable total chordal-sparing mitral valve replacement with a bioprosthesis? Recall that 4 years ago at this meeting, the Cleveland Clinic group actually showed a 7-year survival advantage for mitral valve replacement over repair in the sickest of the 5 quintiles.

Dr McGee. That is a very good point.

I think there are some reports of chordal lengthening, but that currently is not done at the Cleveland Clinic. In certain patients I think a chordal-sparing mitral valve replacement is a good treatment. The majority of patients with ischemic MR, I think, will benefit from a ring annuloplasty, but patients with bileaflet tethering, severe LV dysfunction, and very complex jets, who are extremely sick, would most likely be best served by a chordalsparing replacement with a bioprosthetic valve.

Dr Miller. I agree, and they certainly do not live long enough to need a mechanical valve. Historically, the very poor results we all remember after mitral valve replacement and coronary artery bypass grafting from decades ago might have been due to suboptimal myocardial protection and cutting out the whole valve and subvalvular apparatus.

Dr David Adams (New York, NY). Just another comment about apples and oranges. You used your Carpentier rings predominantly early in the late 1980s. You were not downsizing; your histograms showed your average size was $30 \mathrm{~mm}$, and more were 30, 32, and $34 \mathrm{~mm}$. The majority of your Cosgrove bands were size 26 and size $28 \mathrm{~mm}$. It appears you had a different strategy in terms of size selection over the period of the study. Could you comment on that and how you think that might affect your direct comparison of the 2 rings? 
Dr McGee. Thank you, Dr Adams. Sizing is also a function of surgeon preference. Most surgeons downsize at least 2 sizes, but your point that the Cosgrove bands tended to predominate in the smaller sizes is well taken. That was corrected per the numbers, but we were not able to demonstrate a difference, as you pointed out.

Dr Robert Frater (Broxville, $N Y$ ). Your title implies very distinctly a comparison between different techniques: 2 of them are very standard in being rigid rings, and the third is a technique that requires a great deal of art to make it work at all. You obviously have condemned the pericardial annuloplasty. Would it not be fairer to say that "in our hands we were not able to make the pericardial annuloplasty work" rather than saying, given your experience, that it is automatically for everybody else a bad technique?

Dr McGee. Thank you, Dr Frater. One of the problems with looking at the pericardial annuloplasties was that there did not seem to be a systematic way of sizing them, and there was a lot of variability in that. From our understanding, most were sized to a 26-mm sizer, but that is one of the problems. It is not a standardized method, and because of that, it is hard to reproduce.

Dr Alain Carpentier (Paris, France). Well, I just rise to give a small technical recommendation; that is, we all know that in ischemic valvular disease there is a predominant dilatation in the P3 area, and as pointed out by the previous speaker, you use, in this case, pledget-supported sutures. Another alternative that I like to use in this particular area is a double-roll suture. In other words, if you place 2 rolls of sutures, then you prevent the potential ring dehiscence.

Dr Thoralf Sundt III (Rochester, Minn). Did I understand one of your final slides to show no correlation between annuloplasty technique and survival?

Dr McGee. Yes, there was no difference in terms of survival when it was corrected.

Dr Sundt. When it was corrected?

Dr McGee. For patient factors.

Dr Sundt. Therefore, if there is a profound difference in residual MR according to technique and no difference in survival according to technique, does that not imply that there is no correlation between survival and correction of the MR?

Dr McGee. We did not look specifically at survival and recurrent MR, because after extensive discussions with Dr Blackstone, we are not aware of a way to do that with the current statistical methodology.

\section{Online-www.aats.org}

Now you can get The Journal of Thoracic and Cardiovascular Surgery online. The Journal online brings you faster delivery time, easy searching of current and back issues, links to PubMed, AATS, WTSA, and other important sites, and more. Visit the Journal online today.

\section{Receive tables of contents by e-mail}

To receive the tables of contents by e-mail, sign up through our Web site at http://www.mosby.com/jtcvs

Choose E-mail Notification

Simply type your e-mail address in the box and click the Subscribe button.

Alternatively, you may send an e-mail message to majordomo@mosby.com.

Leave the subject line blank and type the following as the body of your message: subscribe jtcvs_toc

You will receive an e-mail to confirm that you have been added to the mailing list.

Note that TOC e-mails will be sent out when a new issue is posted to the Web site. 


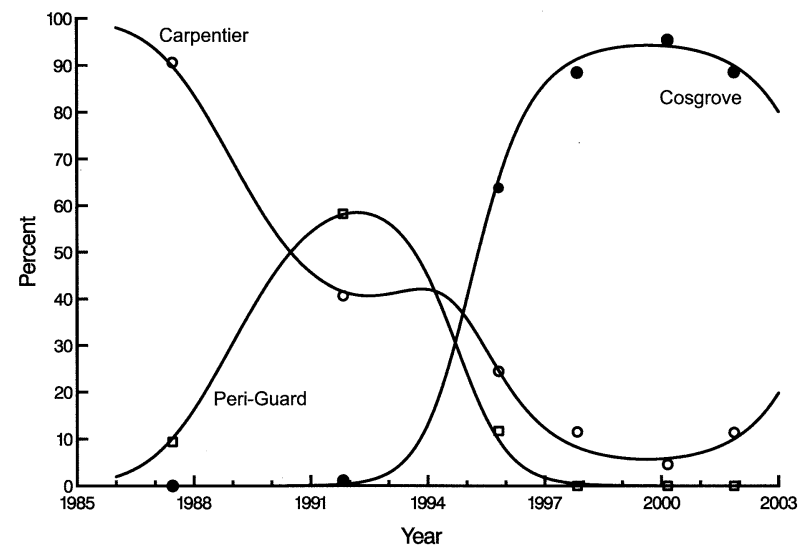

Electronic Appendix 1. Annuloplasty type use by calendar year. Proportion of patients receiving Carpentier-Edwards classic annuloplasty ring (open circles), Cosgrove-Edwards annuloplasty system (filled circles), and Peri-Guard bovine pericardial annuloplasty (open squares) by year of operation.

\section{Appendix 1}

Variables used in analyses

\section{Preoperative}

Demographic

Symptoms

Ventricular dysfunction

Mitral valve pathophysiology Other valve pathophysiology Cardiac comorbidity

Noncardiac comorbidity

Coronary anatomy

Experience Intraoperative Procedure
Age $(\mathrm{y})$, sex, weight $(\mathrm{kg})$, height $(\mathrm{cm})$, body surface area $\left(\mathrm{m}^{2}\right)$, body mass index $\left(\mathrm{kg} \cdot \mathrm{m}^{-2}\right)$ New York Heart Association functional class (I-IV), emergency operation, acute myocardial infarction, remote myocardial infarction

Degree of left ventricular dysfunction ( $1=$ none, $2=$ mild, $3=$ moderate, $4=$ severe $)$, wall motion (anterior, posterior, septal, lateral, inferior)

Jet direction (central, anterior, posterior, complex), mitral regurgitation

Aortic regurgitation, tricuspid regurgitation

Atrial fibrillation, complete heart blocker-pacer, ventricular arrhythmia, prior cardiac operation, emergency operation, no. of previous cardiac operations

Insulin-treated diabetes, non-insulin-treated diabetes, treated diabetes, history of peripheral vascular disease, history of smoking, carotid disease, chronic obstructive pulmonary disease, hypertension, renal disease, creatinine $\left(\mathrm{mg} \cdot \mathrm{dL}^{-1}\right)$, blood urea nitrogen $\left(\mathrm{mg} \cdot \mathrm{dL}^{-1}\right)$, bilirubin $\left(\mathrm{mg} \cdot \mathrm{dL}^{-1}\right)$, hematocrit $(\%)$

Left main trunk disease (\% stenosis), left anterior descending coronary artery system disease (maximum \% stenosis), right coronary artery system disease (maximum \% stenosis), left circumflex coronary artery system disease (maximum \% stenosis)

Date of operation (years since January 1, 1985)

Annuloplasty type, device size (Carpentier and Cosgrove annuloplasties), coronary artery bypass grafting, internal thoracic artery graft used, tricuspid valve repair, aortic clamp time (min), cardiopulmonary bypass time (min)

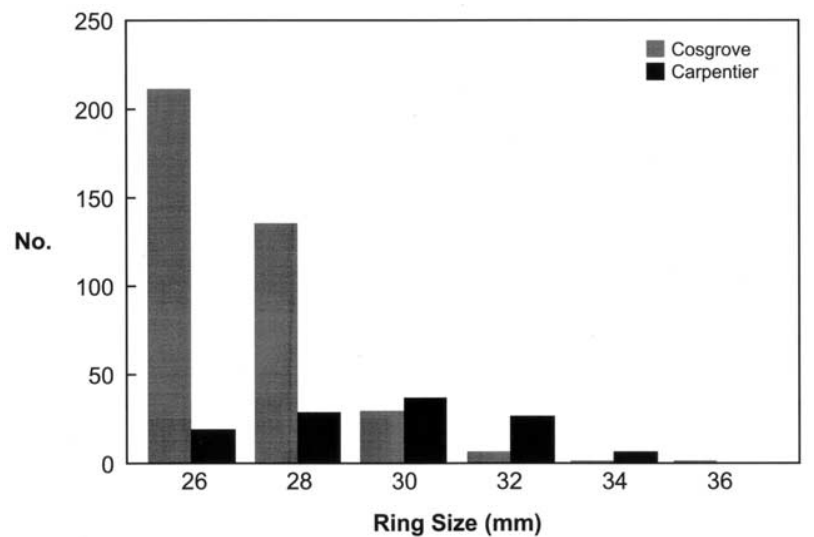

Electronic Appendix 2. Annuloplasty ring size. Number of patients receiving each annuloplasty ring size. 
Electronic Appendix 3.

Patient and procedural characteristics of patients with versus those without postoperative echocardiographic studies

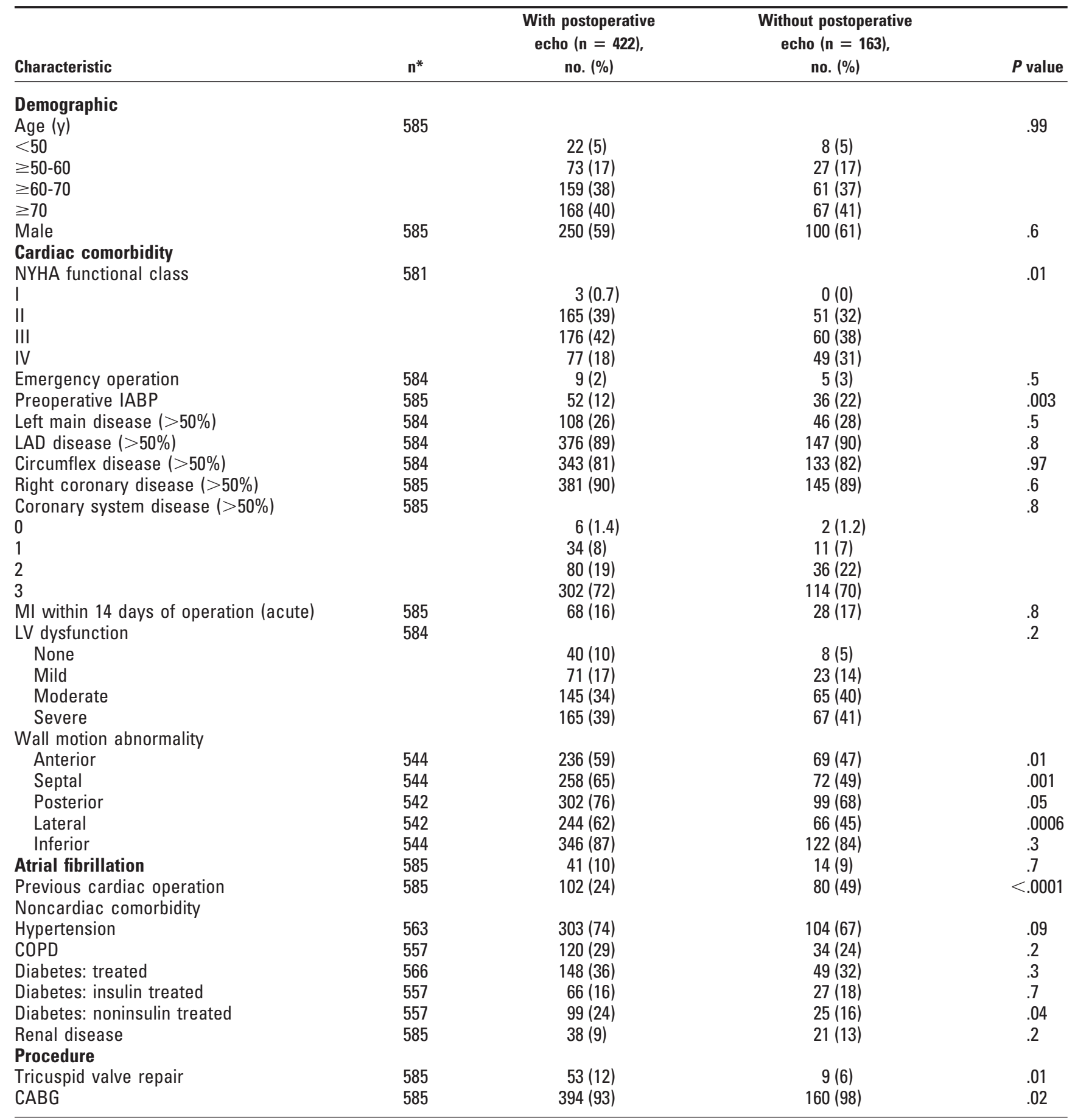

ECHO, Echocardiogram; NYHA, New York Heart Association; IABP, intra-aortic balloon pump; LAD, left anterior descending coronary artery; $M I$, myocardial infarction; $L V$, left ventricular; $C O P D$, chronic obstructive pulmonary disease; $C A B G$, Coronary artery bypass grafting.

*Data available. 
Electronic Appendix 4.

Preoperative mitral valve pathophysiology in patients with versus those without postoperative echocardiographic studies

\begin{tabular}{lccr}
\hline Characteristic & $\begin{array}{c}\text { With postoperative } \\
\text { echo, no. (\%) }\end{array}$ & $\begin{array}{c}\text { Without postoperative } \\
\text { echo, no. (\%) }\end{array}$ & $P$ value \\
\hline MR jet direction (n) & 358 & 119 & .5 \\
Central & $232(65)$ & $81(68)$ & $>.9$ \\
Anterior & $9(2.5)$ & $3(2.5)$ & .1 \\
Posterior & $89(25)$ & $21(18)$ & .2 \\
Complex & $28(8)$ & $14(12)$ & .04 \\
MR grade (n) & 422 & $163(9)$ & \\
$2+$ & $75(18)$ & $87(53)$ & $61(37)$
\end{tabular}

$M R$, Mitral regurgitation.

*Data available.

\section{Electronic Appendix 5. Details of Statistical Models Bias Reduction}

We used PROC LOGISTIC (SAS Institute, Inc, Cary, NC) with generalized logit link and the Cosgrove group as the reference group to generate 2 simultaneous multivariable logistic regression equations that identified factors associated with group membership (Carpentier ring group and Peri-Guard annuloplasty group) relative to the Cosgrove band group by using known preoperative variables (Appendix 1 and Table 1). Continuous and ordinal variables were initially analyzed by means of decile analysis, selecting those transformations of scale that best linearized their relationship to group membership. Having established a parsimonious model, we added other variables representing groups of patients and coronary disease factors that might be related to unrecorded selection factors (saturated model). ${ }^{11}$

Three propensity scores (propensity for receiving Cosgrove band, Carpentier ring, and Peri-Guard annuloplasty) were calculated for each patient by solving the 2 simultaneous multivariable logistic regression equations. Two of the 3 scores and their transformations, where appropriate, were then forced into multivariable analyses as balancing scores to reduce selection bias. ${ }^{10,12}$

\section{Temporal Pattern of Follow-up MR}

Longitudinal ordinal regression was used to analyze the repeated measurements of postoperative and follow-up MR grade (PROC GENMOD, SAS Institute).

\section{Factors Influencing MR Development}

For MR grade measurements made within 6 months of repair, and separately for those made after 6 months, we initially screened variables by using ordinary multivariable logistic regression (PROC LOGISTIC, SAS Institute) and the assumption of independence of observations, with liberal entry (0.2) and retention (0.12) criteria. Because of the limited capability of PROC GENMOD to explore multivariable relations, this analysis was performed simply to identify possible candidates for our repeated measurements model. These candidate variables and their transformations, if any, were entered simultaneously into a longitudinal logistic regression model (PROC GENMOD) and then eliminated one by one until all variables remaining had a $P$ value of .1 or less.

\section{Survival}

A parametric model was used to resolve the number of phases of instantaneous risk of death (hazard function) and to estimate shaping parameters. ${ }^{13}$ Multivariable analysis was performed in the hazard function domain. Preoperative and intraoperative variables used in the analyses are listed in Appendix 1, and variable selection was by bootstrap bagging, with a retention criterion of a $P$ value of .05 or less. ${ }^{14}$ Cosgrove band and Peri-Guard annuloplasty indicators were forced into each hazard phase (leaving Carpentier ring as the reference group), as were the two balancing scores. ${ }^{10,12}$ 


\section{Electronic Appendix 6.}

\section{Risk factors for death after repair}

\begin{tabular}{|c|c|c|c|}
\hline Risk factor & Coefficient \pm SD & $P$ value & Reliability (\%)* \\
\hline \multicolumn{4}{|l|}{ Early hazard phase } \\
\hline Oldert & $0.44 \pm 0.20$ & .03 & 60 \\
\hline Higher NYHA class $\ddagger$ & $0.16 \pm 0.035$ & $<.0001$ & 78 \\
\hline Higher creatinine§ & $-2.3 \pm 0.52$ & $<.0001$ & 92 \\
\hline Higher LV dysfunction grade & $0.37 \pm 0.16$ & .02 & 64 \\
\hline Jet direction: complex & $1.2 \pm 0.43$ & .005 & 49 \\
\hline Earlier date of operation & $-0.12 \pm 0.049$ & .02 & 64 \\
\hline \multicolumn{4}{|l|}{ Annuloplasty type } \\
\hline Cosgrove vs Carpentier & $0.33 \pm 0.46$ & .3 & \\
\hline Peri-Guard vs Carpentier & $0.49 \pm 0.45$ & .3 & \\
\hline \multicolumn{4}{|l|}{ Balancing scores } \\
\hline P_Cosgrove $\|$ & $2.8 \pm 0.93$ & .003 & \\
\hline P_Peri-Guard\# & $1.2 \pm 1.2$ & .3 & \\
\hline \multicolumn{4}{|l|}{ Late hazard phase } \\
\hline Smaller body mass index ${ }^{* *}$ & $1.7 \pm 0.43$ & $<.0001$ & 94 \\
\hline Previous cardiac operation & $0.53 \pm 0.19$ & .02 & 49 \\
\hline Higher creatinine§ & $-1.6 \pm 0.35$ & $<.0001$ & $>99$ \\
\hline Lower hematocrit†† & $-3.9 \pm 0.90$ & $<.0001$ & 53 \\
\hline \multicolumn{4}{|l|}{ Annuloplasty type } \\
\hline Cosgrove vs Carpentier & $-0.44 \pm 0.24$ & .07 & \\
\hline Peri-Guard vs Carpentier & $-0.069 \pm 0.25$ & .8 & \\
\hline \multicolumn{4}{|l|}{ Balancing scores } \\
\hline P_Cosgrove\| & $-0.15 \pm 0.57$ & .8 & \\
\hline P_Peri-Guard\# & $0.66 \pm 0.76$ & .4 & \\
\hline
\end{tabular}

NYHA, New York Heart Association; $L V$, left ventricular.

*Frequency of occurrence in bootstrap models.

†Exp(age/50) exponential transformation.

$\ddagger(\text { New York Heart Association class) })^{2}$ squared transformation.

$\S(1 /$ creatinine) inverse transformation.

|Probability of patient receiving a Cosgrove band.

\#Probability of patient receiving Peri-Guard annuloplasty.

**(1/body mass index) inverse transformation.

t†Ln(hematocrit) logarithmic transformation. 